УДК 340.692

\title{
А. А. Савицкий
}

ГОУ ВПО «Московский государственный юридический университет имени О.Е. Кутафина», Москва, e-mail: savitscky@mail.ru

\section{АКТУАЛЬНЫЕ ПРОБЛЕМЫ НАЗНАЧЕНИЯ И ПРОИЗВОДСТВА СУДЕБНЫХ ОЦЕНОЧНЫХ ЭКСПЕРТИЗ}

Ключевые слова: оценочная деятельность, оценка предприятия (бизнеса), судебная оценочная экспертиза, хозяйственные споры, спорные активы, кадастровая стоимость.

Статья посвящена основным проблемам, возникающим при привлечении оценщиков к участию в судебной оценочной экспертизе. Проанализированы основные концептуальные противоречия в законодательных документах, регламентирующих деятельность оценщиков и судебных экспертов. Уделено внимание объектам, по которым проводится судебная оценочная экспертиза. Показано несоответствие понятийных аппаратов оценочной деятельности и судебной оценочной экспертизы. Отмечено, что наиболее типичными ошибками при проведении экспертизы стоимости предприятия (бизнеса) является применение концепций оценочной деятельности, в частности, использование допущений. Рекомендуется включить судебную оценочную экспертизу в состав класса судебных экономических экспертиз, которые назначаются эксперту-экономисту, обладающему специальными знаниями в области оценочной деятельности.

\section{A. A. Savitsky}

Moscow State Law University named after O.E. Kutafina, Moscow, e-mail: savitscky@mail.ru

\section{CURRENT PROBLEMS OF THE APPOINTMENT AND PRODUCTION OF FORENSIC EVALUATION EXAMINATIONS}

Keywords: appraisal activity, appraisal of an enterprise (business), forensic appraisal examination, economic disputes, disputed assets, cadastral value.

The article is devoted to the main problems that arise when attracting appraisers to participate in a forensic appraisal examination. The main conceptual contradictions in the legislative documents regulating the activities of appraisers and forensic experts are analyzed. Attention is paid to the objects for which a forensic appraisal examination is carried out. The discrepancy between the conceptual apparatuses of appraisal activity and forensic appraisal examination is shown. It is noted that the most typical mistakes in the examination of the value of an enterprise (business) is the application of the concepts of appraisal activity, in particular, the use of assumptions.

В современных условиях в связи с наличием большого числа хозяйственных споров актуальным является необходимость определения рыночной стоимости спорных активов организации либо стоимости в целом предприятия (бизнеса). То же можно отнести и к современным уголовным делам, когда имела место сделка с имуществом, приобретенным по стоимости, не соответствующей рыночной. В уголовном процессе судебные оценочные экспертизы назначаются при расследовании преступлений по таким статьям Уголовного кодекса РФ, как:

- статья 159, часть 4. Мошенничество;
- статья 171. Незаконное предпринимательство;

- статья 172. Незаконная банковская деятельность;

- статья 174. Легализация (отмывание) денежных средств или иного имущества, приобретенных другими лицами преступным путем;

- статья 176. Незаконное получение кредита;

- статья 177. Злостное уклонение от погашения кредиторской задолженности;

- статья 195. Неправомерные действия при банкротстве; 

ство;

- Статья 196. Преднамеренное банкрот-

- статья 197. Фиктивное банкротство;

- статья 199.2. Сокрытие денежных средств либо имущества организации или индивидуального предпринимателя, за счет которых должно производиться взыскание налогов, сборов, страховых взносов;

- статья 199.4. Уклонение страхователяорганизации от уплаты страховых взносов на обязательное социальное страхование от несчастных случаев на производстве и профессиональных заболеваний в государственный внебюджетный фонд;

- прочие.

В арбитражном процессе определение рыночной стоимости тех или иных активов также систематически исследуются по различным категориям дел: в частности, при оспаривании сделок в рамках банкротства, рассмотрении налоговых споров. В гражданском процессе определение рыночной стоимости актуально при спорах физических лиц. Так, например, судебные оценочные экспертизы назначаются при рассмотрении дел возмещения ущерба в результате дорожно-транспортных происшествий, от «заливов». Но наиболее часто судебные оценочные экспертизы назначаются при рассмотрении дел о разделе совместно-нажитого имущества. В рамках экспертного исследования определяется рыночная стоимость ценных бумаг (акций и векселей), долей учредителя в уставном капитале организации, недвижимого имущества, движимого имущества. С 2015г. судебные оценочные экспертизы назначаются в рамках административного судопроизводства по делам об оспаривании размера кадастровой стоимости объектов недвижимости и земельных участков. Исходя из вышеизложенного можно сделать вывод о том, что без назначения и производства судебной оценочной экспертизы вынесение решения как по уголовным делам, так и в рамках гражданского судопроизводства не представляется возможным.

Однако, при всей актуальности судебной оценочной экспертизы, можно констатировать наличие существенных проблем, не осложняющих практику производства судебных оценочных экспертиз. Оценочные экспертизы являются достаточно молодыми - начало становления которых связано с формированием оценочной дея- тельности в РФ (с 1993 г.). В современных условиях можно определить следующие наиболее актуальные проблемы судебной оценочной экспертизы. Так, в настоящее время на нормативно-правовом ровне не закреплено понятие оценочной экспертизы. При этом, в постановлениях и определениях о назначении экспертизы правоприменители систематически именуют указанную экспертизу как стоимостная или оценочная. В современном судопроизводстве не определено место судебной оценочной экспертизы в общей классификации судебных экспертиз. Ведомственные классификаторы судебных экспертиз не предусматривают непосредственно наличие судебной оценочной экспертизы. Вопросы определения рыночной стоимости затронуты в Приказе Минюста РФ от 27 декабря 2012 г. № 237 [1], согласно которому имеет место упоминание вопросов оценки в отдельных родах экспертиз. Так, автотехническая экспертиза рассматривается как «исследование транспортных средств в целях определения стоимости восстановительного ремонта и оценки»; строительно-техническая экспертиза - «исследование строительных объектов и территории, функционально связанной с ними, в том числе с целью проведения их оценки»; товароведческая экспертиза рассматривается как «исследование промышленных (непродовольственных) и продовольственных товаров, в том числе с целью проведения их оценки». Однако данный подход не является неоправданным, поскольку оценочные экспертизы назначаются для исследования рыночной стоимости активов, а стоимость является экономическим понятием, определение которого без специальных экономических знаний не представляется возможным. Таким образом, определение стоимости экспертом-строителей, автотехником или товароведом без участия эксперта судебной экономической экспертизы не представляется возможным. По нашему мнению, судебная оценочная экспертиза является видом рода судебной финансово-экономической экспертизы, при этом, критерием компетенции эксперта является наличие у него специальных знаний в области оценочной деятельности. Вид судебная оценочная экспертиза классифицируется по видам активов: судебная экспертиза стоимости недвижимого имущества, судебная экспертиза стоимости 
автотранспортных средств, экспертиза стоимости объектов интеллектуальной собственности, экспертиза стоимости ценных бумаг (акций, векселей, облигаций) и др. При этом, судебная оценочная экспертиза стоимости предприятия (бизнеса) зачастую носит комплексный характер, поскольку для в состав имущественного комплекса оцениваемой организации могут входить активы, обладающие технологическими особенностями, оценить которые без участия соответствующего специалиста не представляется возможным. Поэтому, на практике систематически встречаются случаи назначения комплексных оценочных, строительно-технические, инженерно-технические, автотехнические экспертиз.

Исследуя актуальные вопросы оценочной экспертизы можно отметить, несоответствие положений оценочной экспертизой и оценочной деятельностью, которые, зачастую, являются причинами расхождения выводов оценщика и эксперта по вопросам стоимости одного и того же актива. Причиной указанных несоответствий являются различные требования законодательства, регулирующего назначение и производство судебных оценочных экспертиз и оценочную деятельность. Оценочная экспертиза регулируется Федеральным законом от 31 мая 2001 г. № 73-Ф3 «О государственной судебно-экспертной деятельности в Российской Федерации» (Ф3 ГСЭД), кодифицированными законами (Уголовный процессуальный кодекс РФ (УПК РФ), Арбитражный процессуальный кодекс РФ (АПК РФ), Гражданский процессуальный кодекс РФ (ГПК РФ), Кодекс административного производства РФ (КАС РФ)), а также постановлениями пленумов Верховного Суда. Законодательство, регламентирующее оценочную деятельность определяется Федеральным законом «Об оценочной деятельности в РФ» № 135-ФЗ от 29 июля 1998 г. (ФЗ-135) и федеральными стандартами оценки (ФСО)). При этом, нормативные акты регулирующие оценочную деятельность могут быть использованы при производстве судебных экспертиз лишь в части понятийного и методического аппарата, только в части, не противоречащей требованиям нормативных актов, регламентирующих судебноэкспертную деятельность.
Ниже приведен разработанный автором понятийный аппарат судебной оценочной экспертизы. Предмет судебной оценочной экспертизы - фактические данные о рыночной стоимости активов, акций, бизнеса субъекта, а также о влиянии на рыночную стоимость активов сделок, оценка которых требует специальных знаний в сфере оценочной деятельности.

Объекты исследования при производстве судебной оценочной экспертизы (на примере исследования рыночной стоимости предприятия (бизнеса)) представляют собой информацию об имуществе организации, доходах организации и данных о сделках на рынке оцениваемого актива.

Задачи судебной оценочной экспертизы: определение рыночной стоимости нематериальных актив, определение рыночной стоимости транспортных средств, определение стоимости недвижимого имущества, оценка финансовых вложений, определение действительной стоимости доли участника при выходе из общества с ограниченной ответственностью, оценка влияния операций на рыночную стоимость активов, исследование влияния на рыночную стоимость операций / сделок организации.

Судебно-экспертные технологии производства судебных оценочных экспертиз - это совокупность осуществляемых в определенной последовательности аналитических процедур, направленных на исследование рыночной стоимости исследуемого актива (недвижимого имущества, движимого имущества, предприятия (бизнеса), объекта интеллектуальной собственности, прав требования), анализ влияния операций (сделок) на рыночную стоимость оцениваемых активов, выполняемых на основе специальных познаний в области оценочной деятельности.

Составляющие элементы судебно-экспертных технологий производства судебных оценочных экспертиз:

- знания методических основ экспертного исследования стоимости активов и методов исследования влияния на стоимость активов операций и сделок собственника;

- критерии оценки промежуточных данных, получаемых в ходе исследования рыночной стоимости оцениваемого актива с помощью методов затратного, доходного и сравнительного подходов; 
- формирования убеждения эксперта в обоснованности выводов о стоимости актива, полученных с использованием различных подходов (проведение проверочных процедур);

- формулирования окончательных выводов о стоимости актива - обобщение результатов исследования, полученных обособленно доходным, затратным и сравнительным подходами в единый результат, а также корректировка полученного результата с учетом особенностей его оборота;

- оформления результатов экспертизы в соответствии с требованиями законодательства о судебно-экспертной деятельности и концепцией судебной экспертологии.

Одна из особенностей судебных оценочных экспертиз заключается в том, что само понятие рыночной стоимости предусматривает предположительный, вероятностный характер. Можно отметить, что вывод о размере рыночной стоимости имущества не может быть категорическим и однозначным, поскольку понятие рыночная стоимость базируется на допущениях и предположениях, что затрудняет его применение в доказывании. Кроме того, определение «рыночная стоимость» всегда вероятный в силу определения законодательства. Так, согласно ст. 3 Ф3-135 (с изменениями и дополнениями), «под рыночной стоимостью объекта оценки понимается наиболее вероятная цена...». Подобный подход противоречит нормам уголовного права. При этом, если, например, рассматривать уголовный процесс, то частью 4 ст. 14 УПК РФ установлено, что обвинительный приговор не может быть основан на предположениях. Частью 3 ст. 14 УПК РФ установлено, что все сомнения в виновности обвиняемого, которые не могут быть устранены в порядке, установленном УПК РФ, толкуются в пользу обвиняемого. Вероятный вывод эксперта о величине рыночной стоимости подтверждает тот факт, что нет полной уверенности в однозначности выводов о величине рыночной стоимости, т. е. имеются обоснованные сомнения в виновности обвиняемого. Данный подход справедлив также и для методических подходов, включающих в себя доходный подход, исследование в рамках которого основано на предположения и допущениях о потенциально возможном получении дохода в будущем (что недопустимо в судебноэкспертной деятельности). В рамках данной статьи мы не оспариваем концептуальные основы оценочной деятельности, однако указанный аргумент обосновывает актуальность совершенствования понятийного аппарата оценочной деятельности и необходимость максимального сближения оценочной деятельности и судебной оценочной экспертизы.

Требует обсуждения и вопрос об использовании информации о событиях, произошедших после даты оценки, которая не может быть использована для определения стоимости объекта оценки только для подтверждения тенденций, сложившихся на дату оценки, в том случае, когда такая информация соответствует сложившимся ожиданиям рынка на дату оценки. При этом принципы судебно-экспертной деятельности требуют полноты всесторонности и исследования [2], что, по сути, вступает в противоречие с постулатом оценочной деятельности.

Также в настоящее время отсутствует соответствие понятийного аппарата оценочной деятельности и судебной оценочной экспертизы. В частности, ст. 25 Федерального закона от 31 мая 2001 г. № 73-Ф3 «О государственной судебно-экспертной деятельности в Российской Федерации» требует указания в заключении эксперта методов исследования [2], ст. 204 УПК РФ - экспертных методик [3]. При этом метод экспертизы (экспертного исследования) - система логических и (или) инструментальных операций (способов, приемов) получения данных для решения вопроса, поставленного перед экспертом, что, по сути, соответствует понятию подхода в оценочной деятельности (подход к оценке представляет собой совокупность методов оценки, объединенных общей методологией [4]). Методом оценки является последовательность процедур, позволяющая на основе существенной для данного метода информации определить стоимость объекта оценки в рамках одного из подходов к оценке [4], что в целом соответствует методике судебно-экспертного исследования - система категорических или альтернативных научно обоснованных предписаний по выбору и применению в определенной последовательности и в определенных существующих или создаваемых условиях методов, приемов и средств для решения экспертной задачи [10]. Таким образом, 
понятие метода экспертного исследования отождествимо с подходом к оценке, а методики экспертного исследования - с методом оценки. Указанное расхождение является существенным при оценке заключения эксперта судебной оценочной экспертизы.

Законодательные акты, определяющие компетенцию эксперта и оценщика, также характеризуются значимыми различия.

Согласно ст. 15 135-Ф3 предусмотрены следующие обязанности оценщика, не актуальные для судебного эксперта (на судебных экспертов эти требования не распространяются):

- быть членом одной из саморегулируемых организаций оценщиков;

- представлять заказчику информацию о членстве в саморегулируемой организации оценщиков;

- представлять саморегулируемой организации оценщиков информацию о юридическом лице, с которым он заключил трудовой договор, а также сведения о любых изменениях этой информации в течение десяти дней с даты заключения трудового договора и/или возникновения изменений;

- представлять ежеквартально в порядке, установленном внутренними документами саморегулируемой организации оценщиков, информацию о подписанных им в указанный период отчетах с указанием даты составления отчета и его порядкового номера, объекта оценки, вида определенной стоимости;

- представлять по требованию заказчика страховой полис и подтверждающий получение профессиональных знаний в области оценочной деятельности документ об образовании;

- хранить копии подписанных им отчетов, а также копии документов и материалов, на основании которых проводилась оценка, на бумажных или электронных носителях либо в форме электронных документов в течение трех лет с даты составления отчета;

- в случаях, предусмотренных законодательством Российской Федерации, предоставлять копии хранящихся отчетов или содержащуюся в них информацию правоохранительным, судебным, иным уполномоченным государственным органам по их требованию;

- по требованию заказчика предоставлять заверенную саморегулируемой организацией оценщиков выписку из реестра членов саморегулируемой организации оценщиков, членом которой он является.

При этом на эксперта оценочной экспертизы указанные требования не распространяются. Согласно требованиям законодательства, эксперт - это лицо, обладающее специальными знаниями и назначенное для проведения исследования и дачи заключения. Однако критерии проверки специальных знаний при назначении экспертизы не предусмотрены.

Компетенция эксперта судебной экономической экспертизы - круг полномочий, предоставленных процессуальным законодательством эксперту судебной экономической экспертизы с одной стороны и круг вопросов в области экономики, финансов, бухгалтерского учета в которых эксперт обладает познаниями, опытом и практическими навыками. Компетентность эксперта судебной экономической экспертизы определяется наличием у эксперта соответствующих специальных знаний - комплекс знаний в области теоретических основ и практических особенностей в сфере экономики, полученных как в процессе обучения, так и на практике (практические навыки), отраженные как в научно-практических источниках, так и в нормативных правовых актах, а также процессуальные знания в области теории и практики производства судебных экономических экспертиз, используемые как во внепроцессуальной так и в процессуальной форме.

Обобщая вышеизложенное, можно выделить следующие требования к эксперту судебной оценочной экспертизы:

- наличие документа, подтверждающего наличие специальных знаний (в частности, диплом переподготовки);

- наличие квалификационного аттестата оценщика, опыт работы в области оценочной деятельности и в производстве судебных оценочных экспертиз, а также наличие сертификации соответствия в области судебной оценочной экспертизы.

Решение данного вопроса может обеспечить только принятие нового закона о судебно-экспертной деятельности, в редакции которого требования к эксперту будут регламентированы более основательно.

В настоящее время можно отметить еще одну наиболее существенную проблему экспертной практики: назначение судебных экспертиз, в рамках которых перед экспер- 
том ставятся вопрос о достоверности отчета об оценке, имеющегося в материалах дела. Подобные вопросы актуальны в случае, если рассматривается дело, когда на основании отчета об оценке были совершены экономически значимые действия. Например, приватизация государственной собственности по заниженной стоимости, внесение имущества в виде взноса в уставный капитал организации по завышенной стоимости и прочие. Также исследование отчета об оценке актуально и в рамках административного судопроизводства по делам об оспаривании кадастровой оценки объектов недвижимости и земельный участков, поскольку основанием для исковых требований является именно отчет об оценке рыночной стоимости указанных объектов. В данных примерах суду представляется целесообразным установить достоверность отчета об оценке. Возможность исследования о достоверности отчета об оценке объекта недвижимости, а также о соответствии отчета об оценке нормам законодательства нормативно определена только в административном судопроизводстве в Постановлении Пленума Верховного Суда РФ от 30.06.2015г. № 28 «О некоторых вопросах, возникающих при рассмотрении судами дел об оспаривании результатов определения кадастровой стоимости объектов недвижимости». У указанном постановлении сказано, что экспертиза должна быть направлена на установление рыночной стоимости объекта недвижимости и включать проверку отчета на соответствие требова- ниям законодательства об оценочной деятельности (ст. 12 и 13 135-Ф3). Нам представляется актуальным исследование рыночной стоимости объекта, однако, вопросы об форме отчета об оценке, о нарушении требований федеральных стандартов оценки, предъявляемых к форме и содержанию отчета, к описанию объекта оценки должны решаться не в рамках судебной экспертизы, а в процессе экспертизы (внесудебной) саморегулируемой организации оценщиков. Таким образом, по большинству указанных параметров эксперт не имеет процессуальной возможности выразить мнение об отчете об оценке.

Таким образом, для актуализации судебной оценочной экспертизы и нивелировании расхождений выводов, полученных в процессе оценки и судебной оценочной экспертизы необходимо осуществление следующих мероприятий:

1) обеспечение судебной оценочной экспертизы унифицированным понятийным аппаратов (определить предмет, понятие, задачи, а также классификацию судебных оценочных экспертиз);

2) разработать единые методические подходы к производству судебных оценочных экспертиз на основе подходов к оценке, не противоречащие подходам оценочной деятельности, не противоречащие нормам процессуального права;

3) провести мероприятия, направленные на сближение оценочной экспертизы и оценочной деятельности в РФ.

\section{Библиографический список}

1. Приказ Минюста России от 27.12.2012 N 237 (ред. от 13.09.2018) «Об утверждении Перечня родов (видов) судебных экспертиз, выполняемых в федеральных бюджетных судебно-экспертных учреждениях Минюста России, и Перечня экспертных специальностей, по которым представляется право самостоятельного производства судебных экспертиз в федеральных бюджетных судебно-экспертных учреждениях Минюста России» (Зарегистрировано в Минюсте России 29.01.2013 №26742) [Электронный ресурс]. URL: http://www.consultant.ru/document/cons_doc_LAW_141682/(дата обращения: 05.05.2021).

2. О государственной судебно-экспертной деятельности в Российской Федерации от 31 мая 2001 г. №73-Ф3: принят Гос. Думой Федер. Собр. РФ 5 апр. 2001 г.: одобр. Советом Федерации Федер. Собр. РФ 16 мая 2001 г. [Электронный ресурс]. URL: http://www.consultant.ru/document/cons_doc_LAW_141682/ (дата обращения: 05.05.2021).

3. Уголовно-процессуальный кодекс Российской Федерации от 18 дек. 2001 г. №174-Ф3: принят Гос. Думой Федер. Собр. РФ 22 нояб. 2001 г.: одобр. Советом Федерации Федер. Собр. РФ 5 дек. 2001 г. [Электронный ресурc]. URL: http://www.consultant.ru/document/cons_doc_LAW_141682/ (дата обращения: 05.05.2021). 
4. Приказ Минэкономразвития России от 20.05.2015 N 297 «Об утверждении Федерального стандарта оценки «Общие понятия оценки, подходы и требования к проведению оценки (ФСО N 1)»)», утвержден приказом Минэкономразвития России от 20.05.2015 N 297 [Электронный ресуpc]. URL: http://www. consultant.ru/document/cons_doc_LAW_141682/ (дата обращения: 05.05.2021).

5. Постановление Пленума Верховного Суда РФ от 30.06.2015 N 28 «О некоторых вопросах, возникающих при рассмотрении судами дел об оспаривании результатов определения кадастровой стоимости объектов недвижимости» [Электронный ресурс]. URL: http://www.consultant.ru/document/cons_doc_ LAW_141682/ (дата обращения: 05.05.2021).

6. Россинская Е.Р. Судебная экспертиза в гражданском, арбитражном, административном и уголовном процессе. М.: Норма, 2014.

7. Савицкий А.А. Актуальные проблемы судебной экономической экспертизы // Законы России: опыт, анализ, практика. 2015. № 10.

8. Россинская Е.Р., Савицкий А.А. и др. Судебная экспертиза: типичные ошибки / под ред. Е.Р. Россинской. М.: Проспект, 2012. 544 с.

9. Россинская Е.Р., Галяшина Е.И., Савицкий А.А. и др. Судебно-экспертная деятельность: правовое, теоретическое и организационное обеспечение: учебник для аспирантуры по специальности 12.00.12 «Криминалистика; судебно-экспертная деятельность; оперативно-розыскная деятельность». М.: Норма; Инфра-М, 2017.

10. Россинская Е.Р., Зинин А.М. Экспертиза в судопроизводстве. М.: Проспект, 2016. 544 с. 